\title{
Interrelationship between implant and orthognathic surgery for the rehabilitation of edentulous cleft palate patients: a case report
}

\author{
José Fernando Scarelli LOPES ${ }^{1}$, João Henrique Nogueira PINTO1, Monica Moraes Waldemarin LOPES ${ }^{1}$, Reinaldo \\ MAZOTTINI' ${ }^{2}$, Simone SOARES ${ }^{3}$
}

\begin{abstract}
1- Prosthodontics Sector, Hospital for Rehabilitation of Craniofacial Anomalies - University of São Paulo (HRAC/USP), Bauru, SP, Brazil.
2- Surgery Sector, Hospital for Rehabilitation of Craniofacial Anomalies - University of São Paulo (HRAC/USP), Bauru, SP, Brazil.

3- Department of Prosthodontics, Bauru School of Dentistry, University of São Paulo; Prosthodontics Sector, Hospital for Rehabilitation of Craniofacial Anomalies

- University of São Paulo (HRAC/USP), Bauru, SP, Brazil.
\end{abstract}

Corresponding address: Simone Soares - Setor de Prótese Dentária - Hospital de Reabilitação de Anomalias Craniofaciais - Universidade de São Paulo (HRAC/USP) - Rua Sílvio Marchioni, 3-20 - Vila Nova Universitária - Bauru - SP - Brazil - 17012-900 - e-mail: sisomi@uol.com.br / sisoares@usp.br

Submitted: September 17, 2014 - Modification: November 4, 2014 - Accepted: November 5, 2014

\section{ABSTRACT}

\begin{abstract}
43-year-old woman with a unilateral cleft lip and palate, presenting a totally edentulous maxilla and mandible with marked maxillomandibular discrepancy, attended the Prosthodontics section of the Hospital for Rehabilitation of Craniofacial Anomalies, University of São Paulo for treatment. She could not close her mouth and was dissatisfied with her complete dentures. Treatment planning comprised placement of six implants in the maxilla, four in the mandible followed by prostheses installation and orthognathic surgery. The mandibular full arch prosthesis guided the occlusion for orthognathic positioning of the maxilla. The maxillary complete prosthesis was designed to assist the orthognathic surgery with a provisional prosthesis (no metal framework), allowing reverse treatment planning. Maxillary and mandibular realignment was performed. Three months later, a relapse in the position of the maxilla was observed, which was offset with a new maxillary prosthesis. This isa complex interdisciplinary treatment and two-year follow-up is presented and discussed. It should be considered that this type of treatment could also be applied in non-cleft patients.
\end{abstract}

Keywords: Orthognathic surgery. Cleft palate. Implant-supported dental prothesis.

\section{INTRODUCTION}

Treatment of adult patients with cleft lip and palate who do not receive proper treatment at the appropriate age is challenging for prosthodontists. The situation becomes worse in adulthood if teeth are lost and patients become edentulous, making prosthetic reconstruction even more challenging ${ }^{5}$.

The lack of information and limited surgical and dental expertise often preclude the proper facial reconstruction and dental rehabilitation for patients with clefts presenting maxillomandibular discrepancies and malocclusion in adolescence. The appropriate timing and planning of surgical reconstruction significantly reduce functional and esthetic disorders in patients with cleft lip and palate. Ideally, the treatment of patients with clefts should begin at an early age.
Many patients with clefts are partially or totally edentulous, and this condition is nearly always associated with a deficient maxillomandibular skeletal relationship. Thus, orthognathic surgery for these patients should fulfill the essential needs for prosthesis placement and also re-establish balance in the facial architecture, which is fundamental to stability ${ }^{3}$.

Studies have demonstrated that the functionality of the stomatognathic system is significantly reduced in patients with complete dentures compared with that in individuals with natural teeth $^{14}$. Endosseous implants increase the treatment efficacy of edentulous patients, who may be rehabilitated by the placement of four to six implants, followed by fabrication of an implantsupported fixed partial denture. Since the 1990s, implants have been used to restore acquired and 
developmental maxillocraniofacial defects, including the rehabilitation of patients with clefts ${ }^{18}$.

In 1995, Posnick and Tompson ${ }^{15}$ reviewed the complications and long-term results of a consecutive series of adolescents with clefts who underwent primary repair in childhood and later developed maxillary deformity and malocclusion requiring orthognathic surgery. The methods used to manage maxillary deformity, malocclusion, residual oronasal fistula, and bone defects in these adolescents were safe and reliable and offered the patients an enhanced quality of life.

These aforementioned problems affect patients' psychosocial well-being, function, and esthetics, to some extent impairing their ability to integrate into society. A follow-up study of young adults with cleft lip and palate showed that up to $30 \%$ of them experienced psychosocial maladjustment, with highest levels of dissatisfaction with appearance, hearing, speech, dentition, and social life. As for education, occupation, and marital status, the psychosocial difficulties observed during childhood persisted, with consequences in adolescence and adulthood, presenting problems in terms of education, self-confidence, assertiveness, and independence, which generate inhibition ${ }^{16}$.

Craniofacial morphology in patients with cleft palate shows a short and retrusive maxilla in relation to the cranial base ${ }^{6}$. Also, the mandible is small and retrusive, with an obtuse gonial angle and a steep mandibular plane. The Le Fort I osteotomy is commonly used for correction of maxillary deficiency in patients with and without clefts, but differences in post-operative skeletal stability and soft-tissue changes exist. The tendency toward relapse and the extent of relapse tend to be higher in patients with clefts ${ }^{10}$. Several factors related to the cleft itself, such as surgery, method of fixation, neuromuscular adaptation, and orthodontics, might contribute to the tendency toward relapse?.

Reverse planning is fundamental when implants are used for the rehabilitation of edentulous patients, especially when orthognathic surgery is required. Treatment planning in these cases should focus on the esthetic and functional outcomes expected. The present clinical case involved functional features, mainly, but esthetic concepts were evaluated, since the patient was totally edentulous and could not close her mouth completely.

The rehabilitation of patients with cleft lip and palate at the Hospital for Rehabilitation of Craniofacial Anomalies (HRAC-USP) in Bauru, Brazil, includes interventions by an interdisciplinary team at appropriate times to achieve complete rehabilitation. This paper reports the interdisciplinary orthognathic surgery/prosthesis treatment in a patient presenting marked maxillomandibular discrepancies. The treatment was planned in collaboration by a maxillofacial surgeon and a prosthodontist. Scarce clinical cases are reported in the literature with remarkable maxillomandibular discrepancy in cleft patients.

Intensive scarring and tension of the soft tissue have been reported as potential causes of relapse in patients with clefts ${ }^{13}$.

As Bailey, et al. ${ }^{1}$ (2004) wrote about the stability and predictability of orthognathic surgery, downward movement of the maxilla is troublesome: if the maxilla is moved both forward and downward, the vertical component is likely to relapse, although the horizontal component has a good chance of being retained.

The purpose of this article was to report the interdisciplinary orthognathic surgery/prosthesis treatment in a patient presenting significant maxillomandibular discrepancies and totally edentulous. A surgeon and a prosthodontist planned the treatment. Although this is a rare case, it should be taken into consideration the relevance of interdisciplinary treatments because the beneficial aspects could be more efficient to the patient.

\section{CASE REPORT}

A 43-year-old female patient, presenting unilateral cleft lip and palate (UCLP), sought care at the Hospital for Rehabilitation of Craniofacial Anomalies (HRAC-USP). Her complaints were difficulties in functioning, poor esthetics, and poor prostheses (two complete dentures), since the maxillomandibular relationship was distorted (Figure $1 \mathrm{~A}$ and $\mathrm{B}$ ). Her psychological state was also a concern, and the patient's expectations were high.

Six implants were placed in the maxilla and four in the mandible (Figures 2 and 3). Maxillary and mandibular protocols were planned and mandibular full arch prosthesis was concluded before the orthognathic surgery, to guide the occlusion.

The first prosthesis was fabricated without consideration for the correct maxillomandibular relationship. Conversely, an adequate relationship between the prosthesis with soft tissue and lip support was achieved. This new prosthesis was fabricated in only acrylic resin, without metal framework, and its primary function was anchored to the orthognathic surgery.

Since the maxilla is presented in two segments, the maxillary prosthesis was sectioned to facilitate the orthognathic surgery planning, and leveling the maxilla (Figure 4A). The newly achieved position was registered (Figure $4 \mathrm{~B}$ ) and duplicated, and two casts were obtained and mounted in a semiadjustable articulator (Figure $5 \mathrm{~A}$ ) to aid in the planned surgery (Figure 5B).

During surgery, the maxilla and the mandible were positioned correctly. A guide was used to direct 
this new position, and a new maxillomandibular relationship was established. Note that the implants inserted before the surgery were important in assisting the surgeon to obtain and maintain the suitable maxillomandibular position.
After 3 months, as expected, the maxillomandibular relationship relapsed (Figure 6A). A new maxillary complete prosthesis, with a favorable maxillomandibular relationship and metal framework, was carried out to correct the occlusion

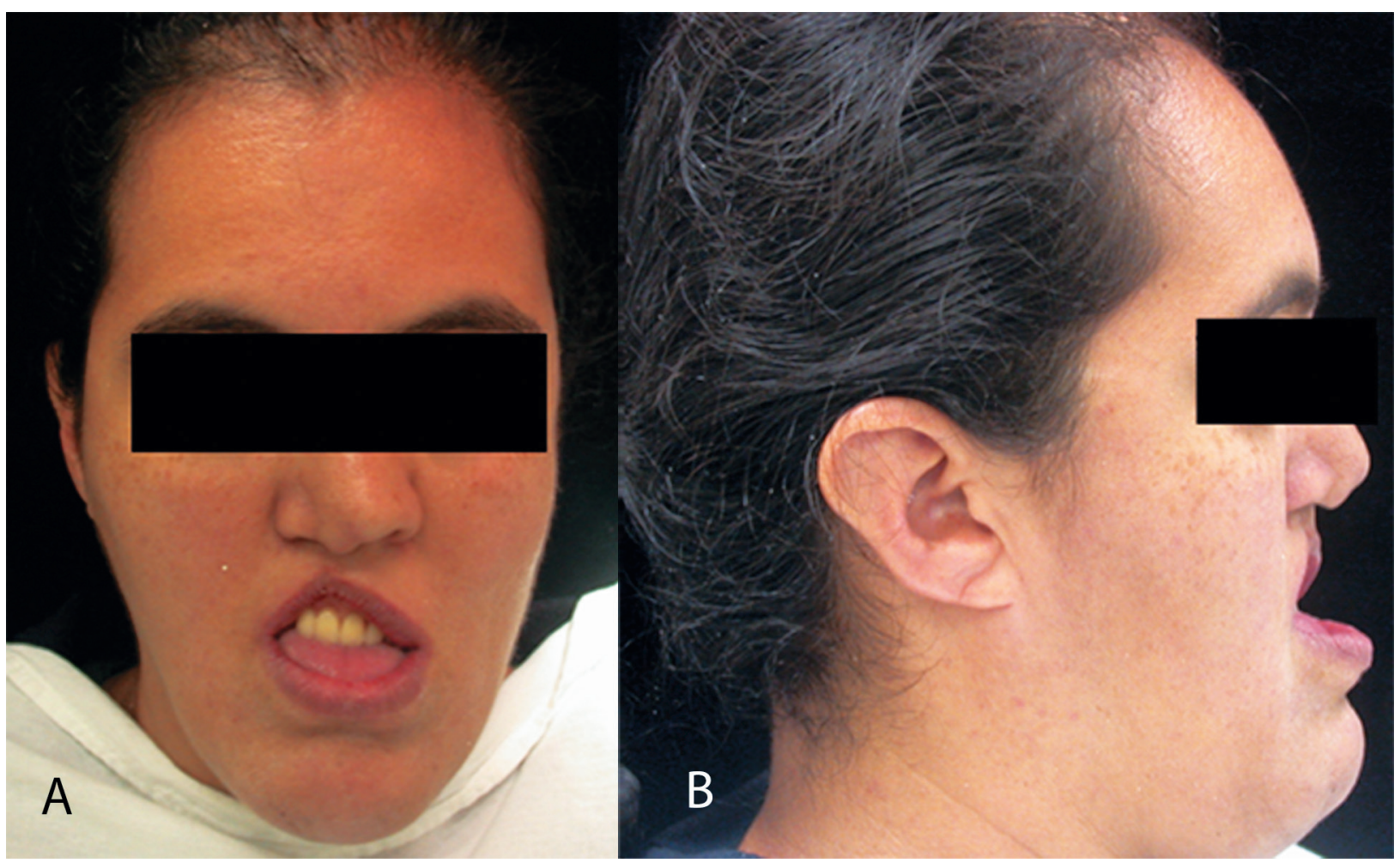

Figure 1- Initial condition presented by the patient when seeking care at the hospital $(A)$ observe the discrepancy in the maxillomandibular relationship (B)

\begin{tabular}{|c|c|}
\hline Tooth/area & Implant dimensions \\
\hline 4 & $3.75 \times 10 \mathrm{~mm}$ \\
\hline 3 & $3.75 \times 13 \mathrm{~mm}$ \\
\hline 9 & $3.75 \times 8.5 \mathrm{~mm}$ \\
\hline 11 & $3.75 \times 11.5 \mathrm{~mm}$ \\
\hline 12 & $3.75 \times 10 \mathrm{~mm}$ \\
\hline 14 & $3.75 \times 10 \mathrm{~mm}$ \\
\hline
\end{tabular}

Figure 2- Location and size of implants placed in the patient's maxilla (Titanium Fix, A. S. Technology, São José dos Campos, São Paulo, Brazil)

\begin{tabular}{|c|c|}
\hline Tooth/area & Implant dimensions \\
\hline 23 & $3.75 \times 15 \mathrm{~mm}$ \\
\hline 20 & $3.75 \times 15 \mathrm{~mm}$ \\
\hline 26 & $3.75 \times 15 \mathrm{~mm}$ \\
\hline 29 & $3.75 \times 15 \mathrm{~mm}$ \\
\hline
\end{tabular}

Figure 3- Location and size of implants placed in the patient's mandible (Conexão, Conexão Sistemas de Prótese, São Paulo, São Paulo, Brazil)

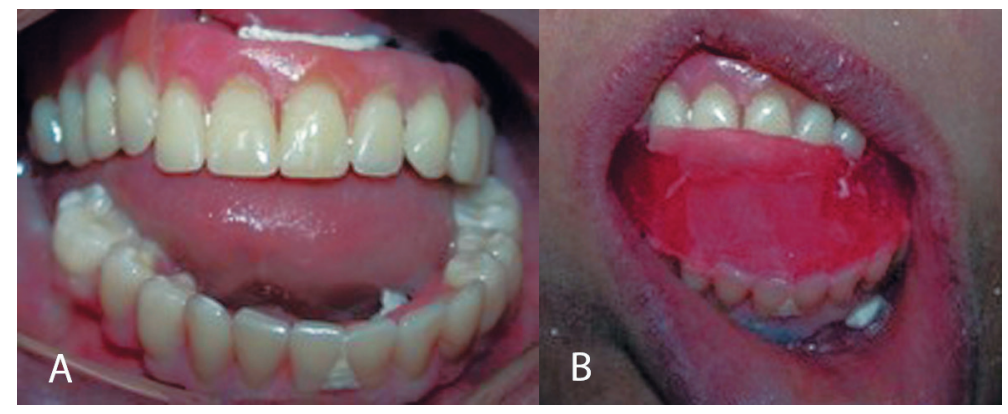

Figure 4- The prosthesis was cut to level the maxilla $(A)$ and new position was registered $(B)$ 


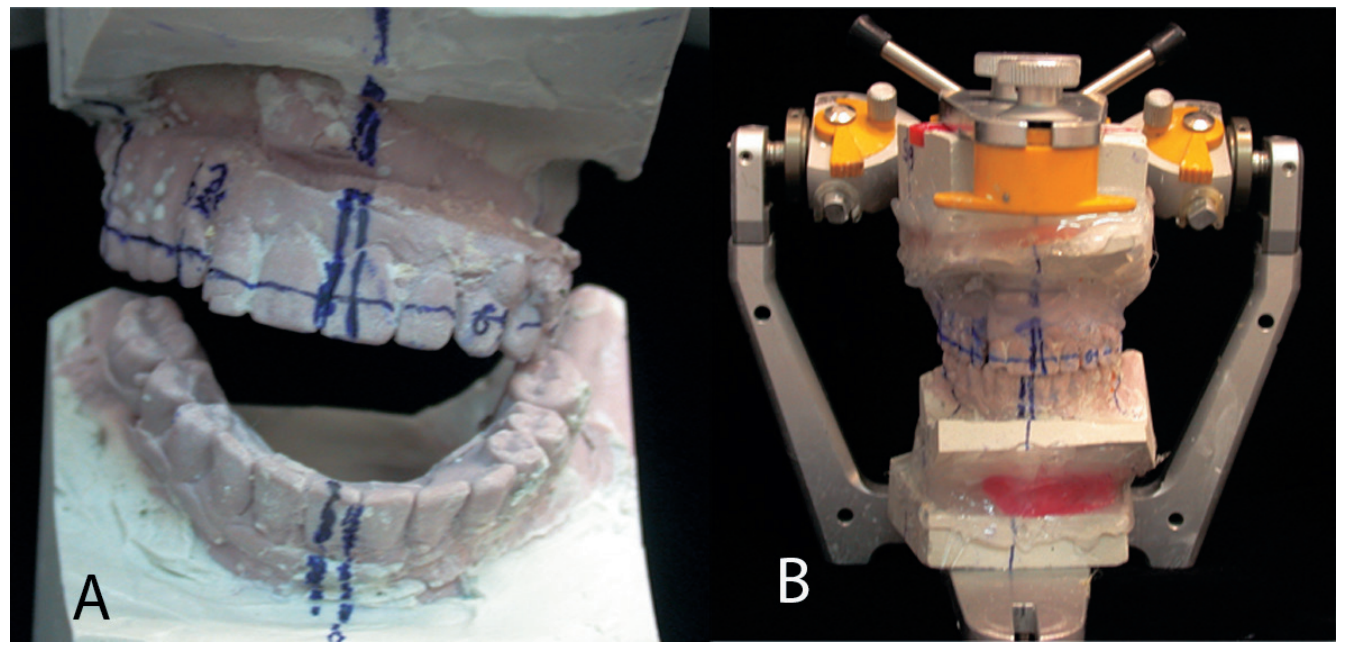

Figure 5- Casts mounted in a semi-adjustable articulator (A) and positioned correctly in the semi-adjustable articulator (B)



Figure 6- Relapse, 3 months after surgery (A), and case concluded, with a correct maxillomandibular relationship (B)
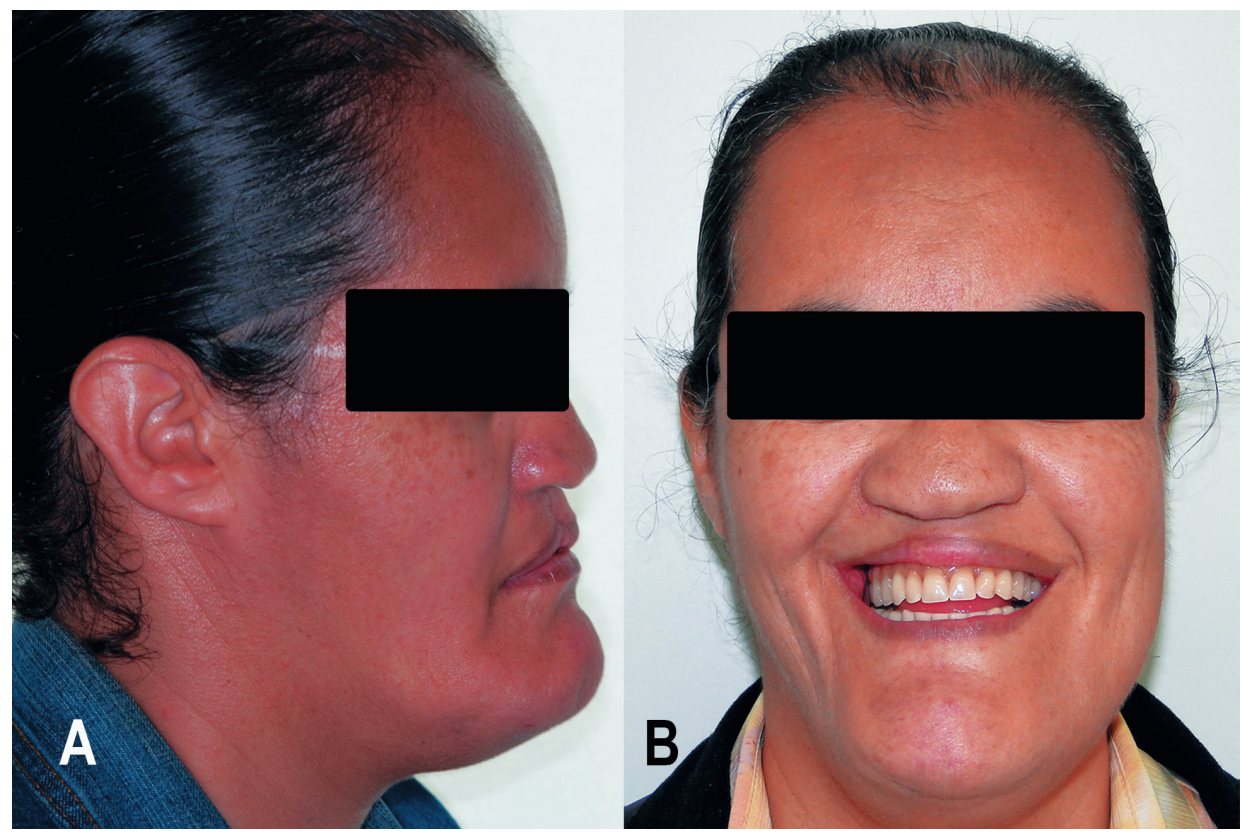

Figure 7- Two years later, lateral $(A)$ and frontal view $(B)$

(Figure 6B).

The case was concluded after orthognathic surgery and the patient was satisfied with the cosmetic and functional outcome and was reintegrated into society. Two years later we can see the stability of the case report (Figures 7A, 7B).

\section{DISCUSSION}

An interdisciplinary team should treat patients with clefts from early ages. These individuals may present esthetic, functional, and psychological problems and occasionally, when they seek 
subsequent treatment, may present remarkable maxillomandibular discrepancies.

In this case report, a 43-year-old woman with unilateral cleft lip and palate could not close her mouth and was dissatisfied with her complete dentures. Six upper and four lower implants were installed; however, her maxillomandibular relationship was incorrect.

Patients who undergo lip and palate repair in childhood often show restricted maxillary growth to a greater or lesser extent, which may cause significant changes in the maxillomandibular relationship. These patients often exhibit a retruded maxilla in relation to the anterior cranial base, compared with individuals without clefts $^{2,9} . \mathrm{Xu}$, et al. ${ }^{19}$ (2014) reported that the maxilla in patients with clefts is shorter and retroclined, which causes a significant maxillomandibular discrepancy.

This problem must be addressed in the treatment planning for patients with clefts ${ }^{17}$. Many cases at HRAC-USP require a combined approach between orthognathic surgery and prosthodontics, as reported in the present case.

Orthognathic surgery to correct facial disharmony is part of the normal follow-up for patients with complete cleft lip and palate. Many factors are taken into account in the planning of corrective surgery, such as facial profile, intermaxillary discrepancies, and the dentoalveolar relationship.

Le Fort I maxillary osteotomy and advancement in patients with cleft lip and palate are the procedures of choice, but have inherent limitations, such as vertical and horizontal relapse ${ }^{7,8}$.

Orthognathic surgery is recommended for patients with cleft lip and palate and having moderate to severe maxillary deficiency after growth. Analysis of unofficial data indicates that around $40 \%$ of patients with complete cleft lip and palate at HRAC-USP undergo orthognathic surgery, especially maxillary advancement surgery or combined maxillary advancement and mandibular retroposition. In such cases, the degree of maxillary advancement required is considered clinically significant, usually around $4 \mathrm{~mm}$; therefore, partial relapses are frequent ${ }^{4}$.

In a clinical study, Kumari, et al. ${ }^{12}$ (2013) evaluated nine patients, pre- and postsurgically, and concluded that Le Fort 1 advancement in surgically repaired cases of cleft lip and cleft palate has inherent potential for relapse. In our case, three months later, we observed relapse and fabricated a new prosthesis for the patient.

In cases with severe maxillomandibular discrepancy, reverse planning allows for analysis of the actual situation, to highlight the importance of orthognathic surgery ${ }^{11}$. Reverse planning is critical before implant insertion, because implants placed without planning can lead to prosthesis failure.
In this case, reverse planning consisting initially of registration of the desired maxillomandibular relationship was used to address the patient's situation. Reverse planning consists of the mounting of models in a semi-adjustable articulator and waxing the case in its intended final position. A guide is fabricated based on this new relationship, then used during surgery to bring the maxilla and mandible into the new position.

Cases of maxillomandibular discrepancies are observed in patients with cleft lip and palate, yet severe cases, such as with limited mouth-opening, as in the present case, are rare, making this case report unique in terms of prosthetic planning and surgery. Other cases with smaller discrepancies may involve surgery, orthodontics, or even prosthodontics to a lesser extent, yet they should also be guided by careful planning, similar to the present report. The present treatment combined orthognathic surgery/prostheses and implants, with esthetic, functional, and psychologically beneficial results.

\section{CONCLUSION}

The interdisciplinary team is important in managing patients with unique maxillomandibular relationships. Only orthognathic surgery can solve these kinds of discrepancies, and reverse planning will aid both the surgeon and the prosthodontist.

\section{CONFLICTS OF INTEREST}

None.

\section{REFERENCES}

1- Bailey LJ, Cevidanes LH, Proffit WR. Stability and predictability of orthognathic surgery. Am J Orthod Dentofacial Orthop. 2004;126:273-7.

2- Bishara SE. Cephalometric evaluation of facial growth in operated and non-operated individuals with isolated clefts of the palate. Cleft Palate J. 1973;10:239-46.

3- Erkan M, Karaçay Ş, Atilla OA, Uzel G, Ülkür E, Yıldırım E. Orthognathic surgery of a patient with oligodontia: alternative technique for intermaxillary fixation. J Craniofac Surg. 2012;23(5):e407-10.

4- Freitas JA, Garib DG, Trindade-Suedam IK, Carvalho RM, Oliveira TM, Lauris, et al. Rehabilitative treatment of cleft lip and palate: experience of the Hospital for Rehabilitation of Craniofacial Anomalies-USP (HRAC-USP) - part 3: oral and maxillofacial surgery. J Appl Oral Sci. 2012;20:673-9.

5- Güven O, Gürbüz A, Baltali E, Yilmaz B, Hatipoğlu M. Surgical and prosthetic rehabilitation of edentulous adult cleft palate patients by dental implants. J Craniofac Surg. 2010;21:1538-41. 6- Heliövaara A, Leikola J, Hukki J. Craniofacial cephalometric morphology and later need for orthognathic surgery in 6-year-old children with bilateral cleft lip and palate. Cleft Palate Craniofac J. 2013;50(2):e35-40.

7- Heliövaara A, Ranta R, Hukki J, Rintala A. Skeletal stability of Le Fort I osteotomy in patients with isolated cleft palate and bilateral cleft lip and palate. Int J Oral Maxillofac Surg. 2002;31:358-63. 
8- Heliövaara A, Ranta R, Hukki J, Rintala A. Skeletal stability of Le Fort I osteotomy in patients with unilateral cleft lip and palate. Scand J Plast Reconstr Surg Hand Surg. 2001;35:43-9.

9- Hermann NV, Kreiborg S, Darvann TA, Jensen BL, Dahl E, Bolund S. Early craniofacial morphology and growth in children with unoperated isolated cleft palate. Cleft Palate Craniofac $\mathrm{J}$. 2002; 39:604-22.

10- Hirano A, Suzuki H. Factors related to relapse after Le Fort I maxillary advancement osteotomy in patients with cleft lip and palate. Cleft Palate Craniofac J. 2001;38:1-10.

11- Jones RH. Orthognathic surgery and implants. Ann R Australas Coll Dent Surg. 2002;16:105-8.

12- Kumari P, Roy SK, Roy ID, Kumar P, Datana S, Rahman S. Stability of cleft maxilla in Le Fort I maxillary advancement. Ann Maxillofac Surg. 2013;3:139-43.

13- Meazzini MC, Basile V, Mazzoleni F, Bozzetti A, Brusati R. Longterm follow-up of large maxillary advancements with distraction osteogenesis in growing and non-growing cleft lip and palate patients. J Plast Reconstr Aesthet Surg. 2015;68:79-86.
14- Mishellany-Dutour A, Renaud J, Peyron MA, Rimek F, Woda A. Is the goal of mastication reached in young dentates, aged dentates and aged denture wearers? Br J Nutr. 2008;99:121-8. 15- Posnick JC, Tompson B. Cleft-orthognathic surgery: complications and long-term results. Plast Reconstr Surg. 1995;96(2):255-66.

16- Roberts RM, Mathias JL. Psychosocial functioning in adults with congenital craniofacial conditions. Cleft Palate Craniofac J. 2012;49:276-85.

17- Scheuer HA, Höltje WJ, Hasund A, Pfeifer G. Prognosis of facial growth in patients with unilateral complete clefts of the lip, alveolus and palate. J Craniomaxillofac Surg. 2001;29(4):198-204. 18- Wang F, Wu Y, Zou D, Wang G, Kaigler D. Clinical outcomes of dental implant therapy in alveolar cleft patients: a systematic review. Int J Oral Maxillofac Implants. 2014;29(5):1098-105.

19- Xu Y, Yang C, Schreuder WH, Shi J, Shi B, Zheng Q, Wang Y. Cephalometric analysis of craniofacial morphology and growth in unrepaired isolated cleft palate patients. J Craniomaxillofac Surg. 2014;42:1853-60. 